RU Ассоциативный прайминг как способ реконструкции профессионально ориентированного иноязычного текста (на примере английского языка)

\begin{abstract}
Алферова Ю. И. правоприменения, связаны с установлением отношений синонимии и гипонимии.

\section{EN Associative Priming as Method to Reconstruct Professionally Oriented Foreign-Language Text (by the Example of the English Language)}

Аннотация. Цель исследования - определить, влияет ли наличие ассоциативных праймов на эффективность реконструкции профессионально ориентированного текста на английском языке. Научная новизна исследования заключается в том, что для получения наиболее полного и объективного представления о точности выбора слов и о представленности компонентов концепта, с которым связан отрывок из текста с пропусками, в языковом сознании учебного билингва были проанализированы компоненты тех же концептов на основе данных лингвистического корпуса (представленность концепта в языковом сознании носителя английского языка), а также проанализированы результаты свободного ассоциативного эксперимента. Результаты исследования показали, что доминирующие когнитивные стратегии, характерные для вторичной языковой личности будущего профессионала

Alferova Y. I.

Abstract. The paper tries to answer the question whether associative primes facilitate reconstruction of the professionally oriented English-language text. Scientific originality of the study lies in the fact that relying on the British National Corpus data (representation of a concept-stimulus in native speakers' linguistic consciousness) and on free associative experiment data, the researcher evaluates adequacy of students' lexical choices and analyses representation of concept components in their secondary linguistic consciousness. The findings indicate that learners' cognitive strategies include identifying synonymic and hyponymic relations.

\title{
Введение
}

Актуальность темы исследования обусловлена необходимостью установления когнитивных стратегий, используемых при восприятии и воспроизведении профессионально ориентированного иноязычного текста учебным билингвом, в связи с чем важно понимание работы механизмов памяти, в частности ассоциативных механизмов. Изучение особенностей восприятия, воспроизведения иноязычного текста неразрывно связано с пониманием ассоциативного характера устройства лексикона человека. Исходя из определения искусственного билингвизма, данного Е. М. Верещагиным, - «искусственный билингвизм обычно возникает в тех случаях, когда обучение вторичному языку проходит в школе или на специальных занятиях» [2, с. 42], под учебным билингвом мы понимаем билингва, изучающего второй язык в учебной обстановке.

В реконструкции профессионально ориентированного иноязычного текста участвуют различные механизмы понимания, в том числе механизмы узнавания, вероятностного прогнозирования, ассоциирования, смысловых замен и т.д. В данном случае мы опираемся на понимание функций слова как единицы индивидуального лексикона в трактовке А. А. Залевской. Так, А. А. Залевская выделяет идентифицирующую, двойственную регулятивную, синтезирующую и прогностическую функции слова, взаимодействие которых обеспечивает понимание слова или текста. В центре нашего внимания идентифицирующая функция слова: «...слово выступает в качестве идентификатора некоторого фрагмента предшествующего опыта в единстве 
его перцептивных, когнитивных и аффективных характеристик, ракурса переживания этого опыта и отношения к нему активного и пристрастного субъекта» [6, с. 331].

Ассоциативный характер организации лексикона позволяет рассматривать ассоциативный прайминг в качестве одного из способов восстановления профессионально ориентированного иноязычного текста.

Теоретической базой исследования послужили работы, посвященные изучению прайминга. Семантический и ассоциативный прайминг находится в центре внимания лингвистов в связи с анализом речевых ошибок и влиянием семантического контекста на лексический поиск (С. И. Горохова), в сфере информационных технологий в связи с «решением задач компьютерного анализа текстовой информации (автоматическое аннотирование, тематическая категоризация и др.») (А. Е. Ермаков, В. В. Плешко) [5], изучаются виды прайминга в связи с механизмами восприятия и перцептивным вниманием, в контексте исследований билингвизма (А. Я. Койфман). «Понятия семантического прайминга и семантической интерференции используются» во многих «современных теориях семантической памяти» [4, с. 120].

В психологии прайминг (от английского глагола prime - инструктировать заранее, заранее снабжать сведениями, давать предшествующую установку) - это «механизм имплицитной памяти, обеспечивающий неосознанное и непреднамеренное влияние однократного воздействия стимула» [3, с. 54] на «реакцию на последующий стимул» [12, р. 3].

Прайминг относится к имплицитной памяти и представляет собой «неосознанное влияние прошлого опыта на поведение и выполнение действий в настоящем» [16, p. 185]. В более широком смысле данное понятие рассматривается как «влияние предшествующего стимула на последующие осознаваемые реакции» [10]. Целевым объектом, или целью, называется предлагаемый стимульный материал, а праймом - предшествовавший ему материал [11]. Эффект взаимосвязи прежнего контекста и скорости опознания последующих стимулов был обнаружен психологами (Д. Е. Мейер, Р. В Шваневелдт) [15]. По мнению А. Н. Назайкина, «прайминг - это влияние предыдущей информации на последующую без активного участия человека, или активация специфических ассоциаций в памяти» [8]. «Прайминг часто представляется более стабильным показателем памяти, чем сознательное воспроизведение, дольше сохраняется и устойчив к изменению условий кодирования, радикально влияющих на уровень воспроизведения» [1, с. 361].

Результаты проведенных экспериментов Р. Граймз и М. Кеан [13] показали, что репрезентации текста, сконструированные реципиентами при понимании предыдущих отрывков текста, оказывают непосредственное влияние на восприятие последующих событий.

«С психолингвистической точки зрения контекст “находится в голове слушающего”, ведь акт интерпретации невозможен без соотнесения языковой информации текста со схемами наличных знаний и убеждений, образующих ряд ассоциирующихся внутренних контекстов» [9, с. 32].

Ассоциативный прайминг нами будет рассматриваться как способ восстановления профессионально ориентированного иноязычного текста.

Слово запоминается вместе с тем контекстом, в котором оно встречается. Частота встречи со словом в определенном контексте влияет на усвоение и «присвоение» этого слова индивидуумом. «Получить доступ к информации намного легче, если ее можно связать с другой известной информацией» [14, p. 153]. Согласно нашим предположениям, наличие ассоциативных праймов в лакунизированном профессионально ориентированном иноязычном тексте должно активизировать определенные лексические единицы, что основано на частоте совместного использования слов в речевом опыте говорящего.

Опорным элементом для процесса восстановления текста может служить ассоциативный прайм, который должен стать актуализатором, соединяющим информацию в единое целое. Имеющиеся в тексте ассоциативные праймы позволяют использовать для восстановления предложений в тексте лексические единицы, часто встречающиеся в профессиональном контексте.

Актуален вопрос, какие типы связей задействованы для поиска слова во внутреннем лексиконе при реконструкции профессионально ориентированного иноязычного текста. Предполагается, что слово, относящееся к сфере правоприменения и часто использующееся в устойчивых профессионально ориентированных терминосочетаниях, активизирует лексические единицы одного тематического поля. Ассоциативный прайминг должен облегчить обработку искомого слова в тексте.

Цель обусловила объект - тип связи между словом-стимулом и ассоциативной реакцией при проведении свободного ассоциативного эксперимента; между праймом, искомым словом и ответом респондентов при заполнении пропусков в тексте; между словом и актуализированными лексическими единицами по данным лингвистического корпуса. Предметом исследования послужили лексические единицы, актуализированные искомыми словами или словами-стимулами.

Для получения наиболее полного и объективного представления о точности выбора слов и о представленности компонентов концепта, с которым связан отрывок из текста с пропусками, в языковом сознании учебного билингва были проанализированы компоненты тех же концептов на основе данных лингвистического корпуса (представленность концепта в языковом сознании носителя английского языка), а также проанализированы результаты свободного ассоциативного эксперимента.

Для достижения цели был определен круг задач: 1) определить когнитивные стратегии, используемые обучающимися при реконструкции профессионально ориентированного текста на английском языке; 2) выявить когнитивные стратегии, которые отвечают за построение лексикона в сознании учебного билингва; 3) определить актуальные компоненты концептов, репрезентированных словами-стимулами, в контекстах лингвистического корпуса. 
В качестве методов использовались метод контекстуального анализа, сравнительный анализ, метод свободного ассоциативного эксперимента.

Практическая значимость работы: материалы исследования могут быть использованы в вузах гуманитарного направления при изучении спецкурсов и спецсеминаров по психолингвистике, когнитивной лингвистике. Полученные данные могут найти применение в процессе учебно-методической деятельности при создании учебников, учебных пособий по английскому языку для профессиональных целей (например, для специалистов правоприменения).

Данное исследование может быть востребовано специалистами, изучающими особенности восприятия, воспроизведения профессионально ориентированного иноязычного текста, стратегий языкового поведения учебных билингвов, психолингвистами.

Исследование включало в себя несколько этапов: работа с лингвистическим корпусом, проведение свободного ассоциативного эксперимента, анализ реконструкции текста.

Свободный ассоциативный эксперимент был проведен с целью сопоставления актуализированных компонентов концептов вне профессионального контекста с данными, полученными после реконструкции профессионально ориентированного текста.

Респондентами в свободном ассоциативном эксперименте являются 52 обучающихся вторых курсов Омской академии МВД России (2017, 2018 и 2019 года набора). Выбор слов-стимулов для свободного ассоциативного эксперимента был определен тематикой текста, подготовленного для задания на заполнение пропусков. В контекстуальном задании на заполнение пропусков в тексте “Observation of a Crime Scene” («Осмотр места происшествия») [7, с. 180-182] эти понятия либо являлись искомыми словами, либо могли оказаться лексемой, наводящей на поиск необходимого лексического варианта (ассоциативным праймом). Свободный ассоциативный эксперимент предшествовал изучению темы «Осмотр места происшествия».

Список слов-стимулов включал в себя слова assessment (оценка), area (территория, район), јury (присяжные), judge (судья), trial/court (суд), photograph (фотография, фотографировать), technological (технологический), information (информация), investigator (следователь), suspect (подозреваемый), warrant (ордер), crime (преступление), evidence (доказательства). Эти же слова в профессионально ориентированном тексте на английском языке, предложенном для восстановления, выступали либо в качестве ассоциативных праймов, либо искомых слов.

Поскольку респонденты восстанавливали связный текст, то не были разделены предложения, в которых требовалось заполнить пропуски или где находились праймы; соответственно, в разных предложениях одно и то же слово могло выступать и в качестве прайма, и в качестве искомого слова; и также в одном предложении могли оказаться несколько искомых слов.

В Таблицах 1-13 справа приводятся результаты свободного ассоциативного эксперимента, слева - итоги выполненного задания на заполнение пропусков в профессионально ориентированном тексте на английском языке. В примерах из текста курсивом выделены искомые слова, подчеркнуты праймы.

\section{Сравнительный анализ}

\section{Assessment (оценка)}

В предлагаемом для восстановления тексте слово “assessment” является искомым.

Пример. The plan of action will vary from crime to crime. It is important that an investigator should do an initial assessment of the scene to ensure that all aspects of the crime are covered [Там же, с. 181]. / План действий может варьироваться в зависимости от преступления. Важно, чтобы следователь дал первоначальную оценку места преступления, чтобы убедиться, что охвачены все аспекты преступления (здесь и далее перевод автора статьи. - Ю. А.).

При проведении свободного ассоциативного эксперимента данное слово являлось словом-стимулом. В Таблице 1 представлены результаты ассоциативного эксперимента на слово-стимул assessment (слева) и результаты работы с текстом (справа).

В 34\% ассоциация и стимул находятся в атрибутивных отношениях и отношениях гипонимии: они представлены видами оценки. При этом $24 \%$ ассоциаций отражают связь с учебным процессом.

Профессиональная направленность проявилась в 27,3\% ассоциаций (из них непосредственно связь лексемы “assessment” с концептом МЕСТО ПРЕСТУПЛЕНИЯ отражена в 9\% ассоциаций). В 18,18\% ассоциация и стимул находятся в отношениях синонимии.

Анализ лингвистического корпуса показал актуализацию следующих связей слова assessment: объект (что оценивается), в том числе учебные достижения, атрибутивные отношения (где слово assessment является определяемым: additional assessment - дополнительная оценка, effective assessment - эффективное оценивание), атрибутивные отношения (где слово assessment само является определением: the assessment criteria - критерии оценки), assessment procedures - процедура оценивания.

Таким образом, исходя из результатов свободного ассоциативного эксперимента, можно утверждать, что ассоциативные праймы scene, initial, investigator актуализируют в языковом сознании учебного билингва искомое слово assessment.

Прайм initial, являясь определением к искомому понятию, соответствует атрибутивным связям, обнаруженным в большом количестве в лингвистическом корпусе. 
Таблица 1. Assessment

\begin{tabular}{|c|c|c|c|}
\hline $\begin{array}{c}\text { Результаты } \\
\text { ассоциативного эксперимента }\end{array}$ & \multicolumn{3}{|c|}{ Текст } \\
\hline аssessment & искомое & ответы респондентов & прайм \\
\hline $\begin{array}{c}\text { разновидности оценки (гипонимия) }-34 \% \\
\text { (в том числе 24\% имеют отношение } \\
\text { к учебному процессу) }\end{array}$ & assessment & $\begin{array}{c}\text { assessment/evaluation (оценка) } \\
\text { точный ответ } \\
\text { или синоним - 100\% }\end{array}$ & $\begin{array}{c}\text { initial (первичная), } \\
\text { scene (место), } \\
\text { investigator (следователь) }\end{array}$ \\
\hline профессиональная ориентированность $-27,3 \%$ & & & \\
\hline синонимы - 18,18\% & & & \\
\hline
\end{tabular}

\section{Area (территория, район)}

В предлагаемом для восстановления тексте слово “агеа” является в одном случае праймом, в другом - искомым словом. При проведении свободного ассоциативного эксперимента данное слово являлось словомстимулом.

Пример. The crime scene search should cover the entire area within the crime scene boundaries, but the areas surrounding the crime scene within reasonable proximity to it should also be taken into consideration. It is the central area where an illegal act took place and usually the starting point of any investigation [Там же]. / Осмотр места преступления должен охватывать всю территорию в пределах границ места преступления, но следует также принимать во внимание и участки, прилегающие к месту преступления. Это центральное место, где было совершено противоправное деяние, и обычно оно является отправной точкой каждого расследования.

Ядро ассоциативного поля area (50\%) по результатам свободного ассоциативного эксперимента составляют синонимы, что совпадает с решением, предложенным курсантами по заполнению пропусков в тексте (например, ассоциация place), и свидетельствует об устойчивых связях в языковом сознании учебного билингва на основе синонимии. Профессиональная направленность отражена в 14,3\% ассоциаций (см. Табл. 2). Таблица 2 содержит результаты ассоциативного эксперимента на слово-стимул агеа (слева) и результаты работы с текстом (справа).

Анализ лингвистического корпуса показал, что атрибутивные отношения, где слово агеа является определяемым, представляют доминирующий тип связи (например, a remote area (отдаленный район), research area (область исследования), the disaster area (зона бедствия), a very multi-cultural area (очень многокультурный район)).

Таблица 2. Area

\begin{tabular}{|c|c|c|c|}
\hline $\begin{array}{c}\text { Результаты } \\
\text { ассоциативного эксперимента }\end{array}$ & \multicolumn{3}{|c|}{ Текст } \\
\hline area & искомое & ответы респондентов & прайм \\
\hline синонимы - 50\% & area & синонимы (83\%), оценка & $\begin{array}{c}\text { act (деяние) / take place } \\
\text { (происходить) / where (где) }\end{array}$ \\
\hline $\begin{array}{c}\text { профессиональная направленность - 14,3\% } \\
\text { (действия следственно-оперативной группы, } \\
\text { направленные на охрану места происшествия) - } \\
\text { например, «оцепление» }\end{array}$ & $\begin{array}{l}\text { surrounding } \\
\text { (окружаю- } \\
\text { щие) }\end{array}$ & $\begin{array}{c}\text { точный ответ (85\%), синоним, } \\
\text { реакция на прайм } \\
\text { (crime scene), выраженная } \\
\text { номинацией действий } \\
\text { следователя }\end{array}$ & $\begin{array}{c}\text { area (территория, район), } \\
\text { crime scene } \\
\text { (место преступления) }\end{array}$ \\
\hline
\end{tabular}

Следующие концепты, как относящиеся к одному семантическому полю (суд, судебный процесс), рассматриваются нами совместно. Это концепты JUDGE, TRIAL, COURT, JURY.

\section{Judge (судья), trial (суд, судебный процесс), court (суд), јury (присяжные)}

В предлагаемом для восстановления тексте слово “јury” является праймом. Искомыми словами были “judge” и “court”. При проведении свободного ассоциативного эксперимента в качестве слов-стимулов из данной области выступали слова “trial” и “jury”.

Пример. Pictures and videotapes help CSI remember details and help jury, judge and prosecutor visualize the scene [Там же]. / Фотографии и видеозаписи помогают следователю, который осматривает место преступления, запомнить детали, а присяжным, судье и прокурору - визуализировать место преступления.

Пример. Notes should detail step by step all actions that the investigator takes in the order in which they happened and may be used in court by both the prosecution and the defense [Там же]. / В протоколе должна быть отражена последовательность действий следователя, и его содержание может быть использовано в суде как стороной обвинения, так и стороной защиты.

По результатам свободного ассоциативного эксперимента ядро ассоциативного поля jury (35,4\%) составляют гиперонимы (люди и т.п.), в том числе в составе дефиниций, предлагаемых респондентами (см. Табл. 3). В Таблице 3 представлены результаты ассоциативного эксперимента на слово-стимул јигу (слева) и результаты работы с текстом (справа).

В 25,8\% ассоциаций отражена связь с законом, судебным процессом. 6,4\% ассоциаций представляют собой негативную оценку (сrazy - сумасшедший, self-killer - самоубийца). 
Участники судебного процесса составили 6\% ассоциативных реакций. Такое же количество ассоциаций приходится на объяснение через функции, выполняемые присяжными.

Анализ лингвистического корпуса показал актуализацию следующих компонентов: функции, выполняемые присяжными (выносить вердикт, решение); участники судебного процесса; судебный процесс.

Несмотря на то, что (контекстуальные) когипонимы слова “jury” составили лишь 6\% ассоциаций при проведении свободного ассоциативного эксперимента, отношения когипонимии при реконструкции профессионально ориентированного иноязычного текста способствовали актуализации связей с искомым словом “јudge”.

Таблица 3. Jury

\begin{tabular}{|c|c|c|c|}
\hline $\begin{array}{c}\text { Результаты } \\
\text { ассоциативного эксперимента }\end{array}$ & \multicolumn{3}{|c|}{ Текст } \\
\hline jury & искомое & ответы респондентов & прайм \\
\hline гипероним - 35,4\% & judge & $\begin{array}{c}\text { точный ответ (90\%) } \\
\text { (другие участники } \\
\text { судебного процесса) - } \\
\text { адвокат }\end{array}$ & $\begin{array}{c}\text { jury (присяжные), } \\
\text { prosecutor (прокурор) }\end{array}$ \\
\hline \multicolumn{4}{|l|}{$\begin{array}{c}\text { связь с законом, } \\
\text { судебным процессом - 25,8\% }\end{array}$} \\
\hline \multicolumn{4}{|l|}{ оценка - 6,4\% } \\
\hline когипоним (в том числе judge) - 6\% & & & \\
\hline функции присяжных - 6\% & & & \\
\hline
\end{tabular}

По результатам свободного ассоциативного эксперимента ядро и ближайшую периферию ассоциативного поля trial составляют синонимы и номинации участников судебного процесса (см. Табл. 4). Таблица 4 содержит результаты ассоциативного эксперимента на слово-стимул trial (слева) и результаты работы с текстом (справа). Совпадение содержания ближайшей периферии и данных лингвистического корпуса в отношении концепта TRIAL позволяет говорить об успешном развитии вторичной языковой личности, сформированности предметно-понятийного компонента концепта, относящегося к профессиональной сфере респондентов.

Анализ лингвистического корпуса показал актуализацию следующих связей слова trial: участники процесса (адвокат, судья), доказательства, обвинение, тип суда (суд по уголовным делам), задержание лица, этап судебного процесса (дача показаний), судебный процесс с участием присяжных, определение вины (невиновности).

Таблица 4. Trial

\begin{tabular}{|c|c|c|c|}
\hline $\begin{array}{c}\text { Результаты ассоциативного } \\
\text { эксперимента }\end{array}$ & \multicolumn{3}{|c|}{ Текст } \\
\hline trial & искомое & ответы респондентов & прайм \\
\hline синоним $-26,7 \%$ & court & $\begin{array}{c}\text { точный ответ (97\%), } \\
\text { процесс, дело }\end{array}$ & $\begin{array}{c}\text { prosecution (обвинение), } \\
\text { defence (защита) }\end{array}$ \\
\hline $\begin{array}{c}\text { участники судебного процесса } \\
\text { (судья, присяжные) - 20\% } \\
\begin{array}{c}\text { другие участники судебного процесса } \\
\text { (например, свидетель, подозреваемый) - } 12 \%\end{array}\end{array}$ & & \\
\hline дело, иск - $11 \%$ & & \\
\hline связь с судебной системой - $10 \%$ & & & \\
\hline атрибутивные отношения -6,7\% & & & \\
\hline связь с законом -6,7\% & & & \\
\hline
\end{tabular}

По результатам свободного ассоциативного эксперимента к ближайшей периферии ассоциативного поля judge относятся ассоциации, отражающие связь с законом (22,72\%) и место работы судьи (22,72\%) (см. Табл. 5). В Таблице 5 содержатся результаты ассоциативного эксперимента на слово-стимул judge (слева) и результаты работы с текстом (справа).

Атрибутивные отношения нашли отражение в 13,6\% ассоциаций (все они касаются качеств судьи: честный, независимый и т.д.), такое же количество составили действия судьи (13,6\%). Собственные дефиниции респондентов составили $4,5 \%$ ассоциаций.

В качестве праймов в тексте выступили слова присяжные и прокурор, которые не нашли отражения в ассоциациях респондентов. Данные свободного ассоциативного эксперимента указывают на сфокусированность языкового сознания учебного билингва (профессионала правоприменения) на месте работы судьи и общей связи с законом.

Анализ лингвистического корпуса показал актуализацию следующих связей слова judge: court (суд), jury (присяжные), circuit / district / federal / an administrative law (окружной / районный / федеральный / по административным делам), injunction/restraining order (судебный запрет), case (дело), appoint (назначать), decision (решение).

Об определенном уровне сформированности вторичной языковой личности свидетельствует совпадение ближайшей периферии ассоциативного поля с актуальными компонентами концепта, отраженными в сознании носителя языка (на основе анализа лингвистического корпуса). Действия судьи и уровни судей 
(федеральный и т.д.), выраженные атрибутивными отношениями в лингвистическом корпусе, составляют периферию ассоциативного поля исследуемого концепта в языковом сознании учебных билингвов. Необходимо отметить, что конкретизация документов, с которыми работает судья, и определенных действий, выполняемых судьями, находит отражение в англоязычном лингвистическом корпусе (а значит, в сознании носителя языка), в сознании вторичной языковой личности учебного билингва отсутствует такая детализация. Отсутствие актуализации в эксперименте данных компонентов, возможно, связано с недостаточной информацией в программе изучения иностранного языка о конкретных действиях судей: тексты, обязательные для изучения в рамках этой темы, носят обобщающий характер.

Таблица 5. Judge

\begin{tabular}{|c|c|c|c|}
\hline $\begin{array}{c}\text { Результаты } \\
\text { ассоциативного эксперимента }\end{array}$ & \multicolumn{3}{|c|}{ Текст } \\
\hline judge & искомое & ответы респондентов & прайм \\
\hline $\begin{array}{c}\text { связь с законом (law (закон), } \\
\text { common law (общее право)) }-22,72 \%\end{array}$ & judge & точный ответ (100\%) & $\begin{array}{c}\text { jury (присяжные), } \\
\text { prosecutor (прокурор) }\end{array}$ \\
\hline место работы судьи (соurt) - $22,72 \%$ & & & \\
\hline действия судьи $-13,6 \%$ & & & \\
\hline качества судьи - $13,6 \%$ & & & \\
\hline дефиниции $-4,5 \%$ & & & \\
\hline
\end{tabular}

\section{Photograph (фотография, фотографировать)}

В предлагаемом для восстановления тексте слово photographing является искомым, при этом в смежных частях текста несколько раз встречается слово photograph. При проведении свободного ассоциативного эксперимента в качестве слова-стимула была выбрана лексема photograph.

Пример. Photographing the crime scene with multiple views of relevant items is necessary. Photographs should be taken before the crime scene has been altered by a more detailed search. Photographs provide visuals of objects in their original states and aid in demonstrating size by means of measuring tools that are also present in the photographs [Там же]. / Необходимо сфотографировать место преступления так, чтобы объекты были видны с разных ракурсов. Фотографии должны быть сделаны до того, как место преступления подвергнется изменениям в результате более детального осмотра. Благодаря фотографиям обеспечиваются визуализация объектов в их первоначальном состоянии и демонстрация размера предметов с помощью изображения измерительных инструментов на фотографии.

Таблица 6 содержит результаты ассоциативного эксперимента на слово-стимул photograph (слева) и результаты работы с текстом (справа). По результатам свободного ассоциативного эксперимента (см. Табл. 6) ядро ассоциативного поля photograph (50\%) составляют синонимы; объект фотографирования отражен в $16,6 \%$ ассоциаций.

6,6\% ассоциаций на стимул photograph отличаются прямой профессионально ориентированной маркированностью. В контексте выбор photographing был правильным и имел профессионально ориентированную связь: фотосъемка на месте преступления.

Непосредственно ассоциаций, совпадающих с ассоциативным праймом в тексте, не выявлено. Тем не менее можно говорить о присутствии многоступенчатых связей между единицами лексикона: в данном случае ассоциация “evidence” (доказательство) имеет отношение к прайму “crime scene” (место преступления).

Анализ лингвистического корпуса показал доминирующей актуализацию следующих связей слова photograph: объект (что фотографируется). Данные связи актуализируются и в сознании русскоязычных респондентов, изучающих английский язык как иностранный, но их можно отнести к ближайшей периферии, что позволяет говорить о совпадении при реконструкции (общеупотребительных) универсальных понятий.

Словарная дефиниция содержит такие компоненты исследуемого концепта, как picture, image, что совпадает с результатами свободного ассоциативного эксперимента (синонимы составляют ядро ассоциативного поля); второй компонент (camera - фотоаппарат) отражен лишь в 6,6\% ассоциаций.

Таблица 6. Photograph

\begin{tabular}{|c|c|c|c|}
\hline $\begin{array}{c}\text { Результаты } \\
\text { ассоциативного эксперимента }\end{array}$ & \multicolumn{3}{|c|}{ Tекст } \\
\hline photograph & искомое & ответы респондентов & $\begin{array}{c}\text { crime scene } \\
\text { (место преступления), } \\
\text { view (ракурс) }\end{array}$ \\
\hline синоним - 50\% & photographing & точный ответ (100\%) & \\
\hline объект (что фотографируют) - $16,6 \%$ & & & \\
\hline профессиональная направленность -6,6\% & & & \\
\hline чем фотографируют (когипоним) -6,6\% & & & \\
\hline
\end{tabular}

Technological (технологический)

В предлагаемом для восстановления тексте слово technological является праймом. При проведении свободного ассоциативного эксперимента слово technological являлось словом-стимулом. 
Пример. Sometimes technological aids for computer-aided drawing are used [Там же]. / Иногда используются технологические средства для автоматизированного составления рисунка.

По результатам свободного ассоциативного эксперимента ядро (33,3\%) ассоциативного поля technological представлено ассоциациями, отражающими отношения когипонимии: компьютер и т.д. Связь с образованием отражена в 29,1\% ассоциативных реакций. Атрибутивные отношения, в том числе отражающие функции, составили 20,8\% реакций. Процент ассоциаций, точно совпадающих с искомой лексемой в тексте (сотputer), составил 14\% (см. Табл. 7). Таблица 7 включает в себя результаты ассоциативного эксперимента на слово-стимул technological (слева) и результаты работы с текстом (справа).

Связь с образовательным процессом, отраженная в ассоциациях, относящихся к ближайшей периферии концепта, объясняется основной деятельностью курсантов - учебой.

Анализ лингвистического корпуса показал актуализацию следующих связей слова technological: инновации, прогресс, развитие, улучшение, изменения, образование, прорыв, преимущества, превосходство. Наиболее частотным является атрибутивный тип связи.

Таблица 7. Technological

\begin{tabular}{|c|c|c|c|}
\hline $\begin{array}{c}\text { Результаты } \\
\text { ассоциативного эксперимента }\end{array}$ & \multicolumn{3}{|c|}{ Текст } \\
\hline technological & искомое & ответы респондентов & прайм \\
\hline когипоним $-33,3 \%$ & computer & точный ответ $(100 \%)$ & technological \\
\hline связь с образованием $-29,1 \%$ & & & \\
\hline атрибутивные отношения + функция $-20,8 \%$ & & & \\
\hline
\end{tabular}

\section{Information (информация)}

В предлагаемом для восстановления тексте слово information является праймом. При проведении свободного ассоциативного эксперимента данное слово являлось словом-стимулом.

Пример. One of the most crucial and obvious source of vital information is the crime scene [Там же, с. 180]. / Одним из наиболее важных и очевидных источников ценной информации является место преступления.

Пример. The information obtained from a crime scene can afford the criminal investigator a proper direction during the overall investigative effort [Там же]. / Информация, полученная с места преступления, может обеспечить следователю надлежащее руководство в ходе всех следственных действий.

Ассоциации на лексему information, составившие ядро ассоциативного поля (68\%), - это конкретные источники информации (text - текст, book - книга, news - новости, people - люди, gossip - слухи). Coтриter можно отнести к источнику информации о преступной деятельности (например, компьютер подозреваемого) или можно рассматривать компьютер как перенос функций Интернета на само устройство, вид информации (в зависимости от носителя) digital и синоним к слову knowledge (см. Табл. 8). В Таблице 8 представлены результаты ассоциативного эксперимента на слово-стимул information (слева) и результаты работы с текстом (справа).

Ассоциации не содержат компоненты концепта, реконструированного на основе словарных дефиниций, где ядром концепта являются «факты».

Необходимо отметить, что при проведении свободного ассоциативного эксперимента индивидуальные ассоциации на лексему information (вне контекста) не содержали номинации действий правоохранительных органов, как это проявилось в задании на заполнение пропусков в тексте (received/obtained) (полученная). Если смысл предложения понятен, то наблюдается стратегия выбора синонима. Так, в оригинале information obtained, курсанты же подбирают слово received.

Таблица 8. Information

\begin{tabular}{|c|c|c|c|}
\hline $\begin{array}{c}\text { Результаты } \\
\text { ассоциативного эксперимента }\end{array}$ & \multicolumn{3}{|c|}{ Текст } \\
\hline information & искомое & ответы респондентов & прайм \\
\hline $\begin{array}{c}\text { конкретизация источника информации -68\% } \\
\text { (из них 12\% приходится на долю technology } \\
\text { (технология), сотрuter (компьютер), } \\
\text { Internet (Интернет)) }\end{array}$ & $\begin{array}{c}\text { source } \\
\text { (источник) }\end{array}$ & $\begin{array}{c}\text { точный ответ (94\%), } \\
\text { номинация действий } \\
\text { следователя - } \\
\text { collection (сбор) }\end{array}$ & information \\
\hline синонимы - 28\% & $\begin{array}{c}\text { оbtained } \\
\text { (полученная) }\end{array}$ & $\begin{array}{c}\text { received (полученная) - } \\
\text { синоним (100\%) }\end{array}$ & \\
\hline
\end{tabular}

Анализ лингвистического корпуса показал актуализацию следующих связей концепта INFORMATION: obtain/obtaining (получать информацию), source of information (источник информации), scraps of information (обрывки информации), lack of information (отсутствие информации), a reward of $\$ 2,500$ to $\$ 5,000$ for information in Django's case (вознаграждение), отсортировать информацию, accuracy of information (точность информации), erroneous information (ошибочная информация), seek information through the Internet (искать информацию в Интернете), valuable information (ценная информация), provide (предоставлять информацию), accessible (доступная информация), information systems (информационные системы).

Среди ассоциаций, характерных для вторичной языковой личности, не наблюдается такого разнообразия, представленного в лингвистическом корпусе. 


\section{Investigator (следователь)}

В предлагаемом для восстановления тексте слово investigator является одним из праймов. При проведении свободного ассоциативного эксперимента данное слово являлось словом-стимулом.

Пример. Strictly speaking, a crime scene is a location wherein physical evidence may be retrieved by law enforcement personnel, crime scene investigators (CSIs) or forensic scientists [Там же, с. 181]. / Строго говоря, место преступления - это место, где сотрудники правоохранительных органов, следователи, специализирующиеся на осмотре места преступления, или криминалисты могут получить вещественные доказательства.

По результатам свободного ассоциативного эксперимента ядро $(35,9 \%)$ ассоциативного поля investigator составляют действия следователя (см. Табл. 9). В Таблице 9 содержатся результаты ассоциативного эксперимента на слово-стимул investigator (слева) и результаты работы с текстом (справа).

При сопоставлении словарной дефиниции и данных свободного ассоциативного эксперимента выявлено совпадение компонента investigation (расследование), но необходимо отметить, что в ассоциациях компонент «действия следователя» представлен намного более детально.

14,8\% ассоциаций отражают связь с областями науки и деятельности (криминология, уголовный процесс и т.д.).

В равных пропорциях (по 10,2\% от всех ассоциаций) актуализируются следующие смыслы: сотрудник полиции, суд и объекты, с которыми следователь работает (например, доказательства, место преступления).

Анализ лингвистического корпуса показал актуализацию следующих связей слова investigator: действия следователя, преступления, расследуемые следователем, должность (старший, частный и др.), качества следователя. В данном случае можно говорить о совпадении ядра концепта INVESTIGATOR в языковом сознании учебного билингва с ядром в сознании носителей языка.

Таблица 9. Investigator

\begin{tabular}{|c|c|c|c|}
\hline \multirow{2}{*}{$\begin{array}{c}\text { Результаты } \\
\text { ассоциативного эксперимента } \\
\text { investigator } \\
\end{array}$} & \multicolumn{3}{|c|}{ Текст } \\
\hline & искомое & ответы респондентов & прайм \\
\hline $\begin{array}{c}\text { конкретизация действий следователя (35,9\%) } \\
\text { (interview - oпрос, interrogation - } \\
\text { допрос, investigation - pacследование, } \\
\text { initiation of (criminal cases) - } \\
\text { возбуждение уголовного дела) }\end{array}$ & $\begin{array}{c}\text { forensic } \\
\text { scientist } \\
\text { (эксперт- } \\
\text { криминалист) }\end{array}$ & $\begin{array}{c}\text { medical expert / } \\
\text { forensic scientist } \\
\text { (судебно-медицинский } \\
\text { эксперт, эксперт- } \\
\text { криминалист) (100\%) - } \\
\text { отношения когипонимии }\end{array}$ & $\begin{array}{c}\text { investigator (следователь), } \\
\text { law enforcement personnel } \\
\text { (сотрудники правоохрани- } \\
\text { тельных органов), physical } \\
\text { evidence (вещественные } \\
\text { доказательства), crime scene } \\
\text { (место преступления), } \\
\text { retrieve (извлекать) } \\
\text { (действия эксперта- } \\
\text { криминалиста ) }\end{array}$ \\
\hline \multicolumn{4}{|l|}{$\begin{array}{c}\text { criminology (криминология), } \\
\text { criminal procedure (уголовный процесс) - } \\
14,8 \%\end{array}$} \\
\hline \multicolumn{4}{|l|}{$\begin{array}{c}\text { fingerprints (отпечатки пальцев), } \\
\text { crime scene (место преступления), } \\
\text { evidence (доказательства), } \\
\text { crime (преступление) - 10,2\% } \\
\end{array}$} \\
\hline court (суд), trial (судебный процесс) - 10,2\% & & & \\
\hline дефиниция - 10,2\% & & & \\
\hline
\end{tabular}

\section{Suspect (подозреваемый)}

В предлагаемом для восстановления тексте слово suspect является искомым. При проведении свободного ассоциативного эксперимента suspect являлось словом-стимулом.

Пример. For instance, the police may use a warrant to search a suspect's home [Там же]. / Например, полиция может использовать ордер для обыска дома подозреваемого.

По результатам свободного ассоциативного эксперимента ядро (33,3\%) ассоциативного поля suspect представлено ассоциациями, отражающими противоправное деяние. Синонимы составили 29,1\% ассоциаций (см. Табл. 10). В Таблице 10 содержатся результаты ассоциативного эксперимента на слово-стимул suspect (слева) и результаты работы с текстом (справа).

Компонент концепта SUSPECT, реконструированного на основе словарных дефиниций «противоправное деяние», входит в состав ядра ассоциативного поля в сознании учебного билингва. Второй базовый компонент словарной дефиниции «виновность»не отражен в ассоциациях.

Анализ лингвистического корпуса показал актуализацию следующих связей слова suspect: действия со стороны органов исполнительной власти (установить личность, обнаружить, арестовать), связь с потерпевшим, действия подозреваемого (например, попытка сбежать).

Можно утверждать, что ассоциативное поле suspect отражает предметно-понятийный компонент концепта, но не в полном объеме (отсутствует компонент «вина»). Несмотря на то, что компонент «действия правоохранительных органов» присутствует лишь в 8\% ассоциаций, при выполнении задания на реконструкцию профессионально ориентированного текста на английском языке все респонденты дали правильный ответ. 
Таблица 10. Suspect

\begin{tabular}{|c|c|c|c|}
\hline $\begin{array}{c}\text { Результаты } \\
\text { ассоциативного эксперимента }\end{array}$ & \multicolumn{3}{|c|}{ Текст } \\
\hline suspect & искомое & ответы респондентов & прайм \\
\hline совершаемое противоправное деяние $-33,3 \%$ & suspect & точный ответ (100\%) & search (обыскивать), \\
home (дом) & & \\
\hline синонимы - 29,1\% & & & \\
\hline место содержания - $12,5 \%$ & & \\
\hline атрибутика - $11 \%$ & & \\
\hline
\end{tabular}

Warrant (opдep)

В предлагаемом для восстановления тексте слово warrant является искомым. При проведении свободного ассоциативного эксперимента существительное warrant являлось словом-стимулом.

Пример. For instance, the police may use a warrant to search a suspect's home [Там же]. / Например, полиция может использовать ордер для обыска дома подозреваемого.

По результатам свободного ассоциативного эксперимента ядро (45\%) ассоциативного поля warrant представлено ассоциациями, отражающими действия, разрешаемые по данному документу (обыск, изъятие, арест) (см. Табл. 11). В Таблице 11 представлены результаты ассоциативного эксперимента на слово-стимул warrant (слева) и результаты работы с текстом (справа).

Следует отметить, что в предлагаемом для восстановления тексте искомыми являются слова “warrant” и “suspect”, а лексема “home” (выступившая в качестве ассоциата на слово “warrant”) является праймом.

Анализ лингвистического корпуса показал актуализацию следующих компонентов концепта WARRANT: действия следственных органов (обыск, изъятие, арест, прослушивание), объяснение документа через функции.

Для учебного билингва актуальны те же компоненты концепта, что представлены в словарных статьях на английском языке и выявлены в лингвистическом корпусе, что свидетельствует о сформированности предметно-понятийного компонента концепта WARRANT в языковом сознании будущего сотрудника правоохранительных органов.

Таблица 11. Warrant

\begin{tabular}{|c|c|c|c|}
\hline $\begin{array}{c}\text { Результаты } \\
\text { ассоциативного эксперимента }\end{array}$ & \multicolumn{3}{|c|}{ Текст } \\
\hline warrant & искомое & ответы респондентов & прайм \\
\hline $\begin{array}{c}\text { действия, разрешаемые данным } \\
\text { документом, - } 45 \%\end{array}$ & warrant & $\begin{array}{c}\text { точный ответ (96\%), } \\
\text { собака, оружие } \\
\end{array}$ & search, use, home \\
\hline гипероним (разрешение) - 20\% & & & \\
\hline $\begin{array}{c}\text { принадлежность области права } \\
(\text { law, legal) }-20 \% \\
\end{array}$ & & & \\
\hline $\begin{array}{c}\text { home - } 10 \% \text { (опосредованная связь - } \\
\text { связующее, но не озвученное звено) - } \\
\text { обыск (search) }\end{array}$ & & & \\
\hline
\end{tabular}

\section{Crime (преступление)}

В предлагаемом для восстановления тексте слово crime является одним из праймов. При проведении свободного ассоциативного эксперимента сrime являлось словом-стимулом.

Пример. This, however, is not to say that the crime scene is necessarily the place where the crime was committed [Там же]. / Это, однако, не означает, что место преступления обязательно является местом, где было совершено преступление.

Пример. In another instance, an offender might kidnap at one location (primary crime scene), transport the victim (the car being a secondary crime scene), commit another crime at a distant location (murder, for instance) and then dispose of the body at a fourth scene [Там же]. / В другом случае преступник может совершить похищение в одном месте («первичное» место преступления), перевезти жертву (автомобиль является «вторичным» местом преступления), совершить другое преступление в отдаленном месте (например, убийство) и затем избавиться от тела в четвертом месте.

По результатам свободного ассоциативного эксперимента ядро (33,3\%) ассоциативного поля crime представлено синонимами и компонентами дефиниций слова (что отражает когнитивные действия учебного билингва по составлению дефиниций). Виды преступлений составили 25,9\% ассоциаций. Субъект преступления отражен в 14,8\% реакций (см. Табл. 12). Таблица 12 содержит результаты ассоциативного эксперимента на слово-стимул crime (слева) и результаты работы с текстом (справа).

Глагол commit (совершать) не актуализировался по результатам свободного ассоциативного эксперимента, но выбор респондентов при восстановлении профессионально ориентированного текста на английском языке был правильным. Можно сказать, что в языковом сознании учебного билингва не наблюдается устойчивой сформированной прямой связи, но она актуализируется в контексте. 
Анализ лингвистического корпуса показал актуализацию следующих связей слова сrime: действие субъекта преступления - совершать, конкретизация преступления (гипонимия), место преступления, причины преступности, уровень преступности, действия правоохранительных органов (снижать), наказание, детектив (как жанр).

Таблица 12. Crime

\begin{tabular}{|c|c|c|c|}
\hline $\begin{array}{c}\text { Результаты } \\
\text { ассоциативного эксперимента }\end{array}$ & \multicolumn{3}{|c|}{ Текст } \\
\hline crime & искомое & ответы респондентов & прайм \\
\hline синонимия - 33,3\% & commit (совершать) & точный ответ (100\%) & $\begin{array}{c}\text { crime (преступление), } \\
\text { crime scene } \\
\text { (место преступления) }\end{array}$ \\
\hline \multicolumn{4}{|l|}{ гипонимия - 25,9\% } \\
\hline \multicolumn{4}{|l|}{ кто совершает? - 14,8\% } \\
\hline \multicolumn{4}{|l|}{ кто расследует? - 3,7\% } \\
\hline $\begin{array}{c}\text { где? - crime scene } \\
\text { (место преступления) }\end{array}$ & & & \\
\hline
\end{tabular}

\section{Evidence (доказательства)}

В предлагаемом для восстановления тексте слово evidence является в одних случаях праймом, в других - искомым понятием. При проведении свободного ассоциативного эксперимента evidence является словом-стимулом.

Пример. Even though the suspect did not commit the crime at that location, evidence of the crime could be found there [Там же]. / Несмотря на то, что подозреваемый не совершал преступления в этом месте, там можно было найти доказательства преступления.

Пример. Comprehensive crime scene processing consists of the following components: developing a plan of action, note taking, crime scene search, crime scene photography, sketching the crime scene, and collection of evidence [Там же]. / Комплексный осмотр места преступления состоит из следующих компонентов: разработка плана действий, ведение записей (протоколирование), поиск на месте преступления, фотографирование на месте преступления, составление эскиза места преступления и сбор доказательств.

Пример. Finally, collecting and packaging evidence must be done [Там же]. / Наконец, необходимо произвести сбор и упаковку доказательств.

Пример. This work requires strict adherence to procedures in order not to make a mistake and damage the evidence [Там же]. / Эта работа требует строгого соблюдения процедур, чтобы не допустить ошибки и повреждения доказательств.

Ядро ассоциативного поля evidence (60\% ассоциативных реакций) представлено ассоциациями, отражающими отношения гипонимии между словом-стимулом и ассоциацией (конкретизация доказательств: fingerprints - отпечатки пальцев, shoeprints - следы обуви, blood - кровь). 28\% составили ассоциации с низкой частотностью, имеющие профессиональную направленность, в связи с чем не представляется возможным сгруппировать их по отдельным категориям (см. Табл. 13). В Таблицу 13 вошли результаты ассоциативного эксперимента на слово-стимул evidence (слева) и результаты работы с текстом (справа).

Таблица 13. Evidence

\begin{tabular}{|c|c|c|c|}
\hline $\begin{array}{c}\text { Результаты } \\
\text { ассоциативного эксперимента }\end{array}$ & \multicolumn{3}{|c|}{ Текст } \\
\hline evidence & искомое & ответы респондентов & прайм \\
\hline $\begin{array}{c}\text { гипонимия (включая атрибутивные } \\
\text { отношения - physical } \\
\text { (вещественные)) -60\% }\end{array}$ & evidence & точный ответ (100\%) & $\begin{array}{c}\text { find (действия } \\
\text { со стороны правоохра- } \\
\text { нительных органов - } \\
\text { находить), suspect } \\
\text { (подозреваемый), сотmit } \\
\text { а сrime (совершить } \\
\text { преступление) } \\
\end{array}$ \\
\hline $\begin{array}{c}\text { одиночные ассоциации, имеющие } \\
\text { профессиональную } \\
\text { направленность, }-28 \%\end{array}$ & $\begin{array}{c}\text { номинация действий } \\
\text { следователя - } \\
\text { collection (сбор) }\end{array}$ & $\begin{array}{c}\text { collection (сбор) / } \\
\text { preservation (сохране- } \\
\text { ние) / save (сохранять) / } \\
\text { packaging } \\
\text { (упаковывание) (100\%) }\end{array}$ & $\begin{array}{c}\text { evidence, crime scene } \\
\text { processing (осмотр места } \\
\text { преступления) }\end{array}$ \\
\hline \multirow[t]{2}{*}{$\begin{array}{c}\text { действия со стороны } \\
\text { правоохранительных органов - 8\% }\end{array}$} & $\begin{array}{c}\text { номинация действий } \\
\text { следователя - } \\
\text { packaging (упаковывание) }\end{array}$ & & $\begin{array}{l}\text { evidence, } \\
\text { collecting (сбор) }\end{array}$ \\
\hline & $\begin{array}{c}\text { номинация действий } \\
\text { следователя - } \\
\text { damage (повредить) }\end{array}$ & & \\
\hline
\end{tabular}

В тексте в связи с искомой лексемой evidence праймом являются номинации действий следователя или эксперта-криминалиста (find - находить, collect - собирать, package - упаковывать), в том числе нежелательных действий (damage - разрушить). Курсанты выполнили задание на заполнение пропусков правильно. 
В тексте праймом выступили номинации действий со стороны правоохранительных органов, тогда как по результатам свободного ассоциативного эксперимента тип связи «действие - объект» отражен в $8 \%$ ассоциаций.

Свободный ассоциативный эксперимент показал актуальность гипонимических отношений (конкретизированы доказательства). Также конкретизированы действия следователей, экспертов-криминалистов. Деятельность представителей закона отражена в лингвистическом корпусе применительно к сторонам в судебном процессе.

Анализ лингвистического корпуса показал актуализацию следующих связей слова evidence: связь с предъявляемым обвинением, действия сторон в процессе (связь «действие - объект»: предъявлять, предоставлять, проверять достоверность), характер доказательств (а именно поддерживающие, недостаточные), действия со стороны преступника или свидетеля (скрывать), отношения синонимии или гипонимии (например, показания).

\section{Заключение}

Проведенный сравнительный анализ соотношения искомого слова, прайма в тексте и ответа респондента при реконструкции профессионально ориентированного текста на английском языке, определение типа связи между словом-стимулом и ассоциатом при проведении свободного ассоциативного эксперимента, а также контекстуальный анализ (на основе данных лингвистического корпуса) позволяют сделать следующие выводы.

В ходе исследования были выявлены следующие доминирующие стратегии при реконструкции текста в том случае, если не был дан точный ответ: 1) синонимия; 2) конкретизация (действий или объектов); 3) когипонимия. При этом точные ответы составили не менее $83 \%$ от всех ответов по всем словам, что позволяет сделать вывод о том, что наличие ассоциативных праймов влияет на эффективность реконструкции профессионально ориентированного текста на английском языке.

Превалирующими когнитивными стратегиями, которые были определены по результатам свободного ассоциативного эксперимента, являются: подбор синонимов (30,7\%), выбор гипонимов (23\%), установление отношений гиперонимии (15,3\%), установление связи «слово-стимул - объект деятельности» (15,3\%), установление связи «слово-стимул - область деятельности» $(7,6 \%)$, установление отношений когипонимии (7,6\%). Сравнительный анализ терминов и общеупотребительных слов позволяет утверждать, что в некоторых случаях преобладающие ассоциации представляют собой компоненты словарных дефиниций (например, jury, judge), в некоторых - наблюдается частичное совпадение (например, suspect - только «противоправное деяние», но не «вина»; crime - «противоправное деяние», но второй базовый компонент «наказание» представлен лишь в единичных реакциях). Из общеупотребительной лексики только ядро ассоциативного поля photograph представлено элементами дефиниции. Ядро ассоциативного поля составили синонимы как в случае с общеупотребительной лексикой, так и в случае с терминами (например, photograph, trial). Гиперонимы составили ядро ассоциативного поля термина jury. Из всех слов-стимулов наиболее подробно представлен концепт СЛЕДОВАТЕЛЬ (что отражает специализацию респондентов); конкретизация улик (ассоциации на слово-стимул evidence) показывает хорошее знание респондентами данной темы (несмотря на то, что свободный ассоциативный эксперимент проводился до ее детального изучения на занятиях по английскому языку). Небольшое различие в лексических единицах, используемых для восстановления части текста, связанной с доказательствами (evidence), может свидетельствовать о наличии в языковом сознании учебного билингва устойчивых связей благодаря частоте употребления подобных словосочетаний. Ассоциативный эксперимент отражает продукт как прямых, так и многоступенчатых связей между единицами лексикона.

Совпадение ответов респондентов при реконструкции текста или ассоциаций, полученных в результате проведения свободного ассоциативного эксперимента на английском языке, с данными лингвистического корпуса (английский язык) свидетельствует об успешном развитии вторичной языковой личности, сформированности предметно-понятийного компонента концепта в каждом конкретном случае.

Можно было предположить, что ассоциативная структура значения слов общего лексического фонда не играет большой роли (при опоре на них) в качестве ассоциативных праймов при восстановлении профессионально ориентированного текста на английском языке в отличие от профессионально ориентированной лексики и терминов. Тем не менее чаще всего, выступая в качестве слов-стимулов, общеупотребительная лексика актуализирует в сознании респондентов, изучающих английский язык как иностранный, ассоциации, совпадающие с контекстом, представленным в лингвистическом корпусе (СОСА), - таким образом, можно утверждать, что ядро или ближайшая периферия исследуемых концептов в языковом сознании учебных билингвов сформированы с приближением к языковому сознанию носителя языка.

Выявленные когнитивные стратегии, используемые при воспроизведении профессионально ориентированного текста на английском языке, анализ типов связей между искомым словом, праймом в тексте и ответом респондента, сопоставление результатов свободного ассоциативного эксперимента с данными лингвистического корпуса позволили проанализировать структуру профессионального лексикона учебного билингва.

Перспективы дальнейших исследований могут быть связаны с изучением особенностей восприятия, воспроизведения профессионально ориентированного иноязычного текста, языкового сознания и стратегий языкового поведения учебных билингвов. Материалы исследования могут быть использованы в вузах гуманитарного направления при изучении спецкурсов и спецсеминаров по психолингвистике, когнитивной 
лингвистике. Полученные данные могут найти применение в процессе учебно-методической деятельности при создании учебников, учебных пособий по английскому языку для профессиональных целей (например, для специалистов правоприменения).

\section{Список источников}

1. Величковский Б. М. Когнитивная наука: основы психологии познания: в 2-х т. М.: Смысл; Академия, 2006. T. 1.448 c.

2. Верещагин Е. М. Психологическая и методическая характеристика двуязычия (билингвизма). М. - Берлин: Директ-Медиа, 2014. 162 с.

3. Владимиров И. Ю., Павлищак О. В. Преодоление фиксированности как возможный механизм инсайтного решения // Современные исследования интеллекта и творчества / под ред. А. Л. Журавлёва, Д. В. Ушакова, М. А. Холодной. М.: Институт психологии РАН, 2015. С. 48-64.

4. Горохова С. И. Влияние семантического контекста на лексический поиск // Вопросы психолингвистики. 2016. № 2 (28). С. 120-131.

5. Ермаков А. Е., Плешко В. В. Ассоциативная семантическая сеть: статистическая модель восприятия и порождения текста [Электронный ресурс]. URL: http://www.dialog-21.ru/digest/2001/articles/ermakov/ (дата обращения: 07.08.2020).

6. Залевская А. А. Слово. Текст. Избранные труды. М.: Гнозис, 2005. 543 с.

7. Малахова М. Н., Смердина Е. Ю., Алферова Ю. И. Law. Police. Society (Право. Полиция. Общество): учебное пособие по английскому языку: в 3-х ч. Омск: Омская академия МВД России, 2014. Ч. II. 268 с.

8. Назайкин А. Н. Эффект прайминга в медиаисследованиях и рекламе [Электронный ресурс]. URL: https://vestnik.journ.msu.ru/books/2010/6/effekt-prayminga-v-mediaissledovaniyakh-i-reklame/ (дата обращения: 20.07.2020).

9. Сазонова Т. Ю., Умеренкова А. В. Эффект обманутого ожидания: лингво-когнитивное моделирование // Вопросы психолингвистики. 2007. № 5. С. 30-32.

10. Тимошенко Е. А. Теоретические и экспериментальные истоки прайминг-эффектов [Электронный ресурс]. URL: http://www.fundamental-research.ru/ru/article/view?id=37310 (дата обращения: 19.11.2020).

11. Фаликман М. В., Койфман А. Я. Виды прайминг-эффектов в исследованиях восприятия и перцептивного внимания // Вестник Московского университета. Серия 14. Психология. 2005. № 4. С. 81-89.

12. Bargh J. A., Chartrand T. L. Studying the Mind in the Middle: A Practical Guide to Priming and Automaticity Research // Handbook of Research Methods in Social Psychology / ed. by H. Reis, C. Judd. N. Y.: Cambridge University Press, 2000. P. 1-39.

13. Grimes-Maguire R., Keane M. T. Evidence of Muddy Knowledge in Reaching for the Stars: Creating Novel Endings to Event Sequences // Proceedings of the Twenty-Sixth Annual Conference of the Cognitive Science Society. Hillsdale, NJ: Erlbaum, 2004. P. 506-510.

14. Hoey M. Lexical Priming. A New Theory of Words and Language. Stroud, United Kingdom: Taylor \& Francis, 2005. XIII+202 p.

15. Meyer D. E., Schvaneveldt R. W. Facilitation in Recognizing Pairs of Words: Evidence of Dependence between Retrieval Operations // Journal of Experimental Psychology. 1971. Vol. 90. № 2. P. 227-234.

16. Schacter D. L., Buckner R. L. Priming and the Brain. Review // Neuron. 1998. Vol. 20. P. 185-195.

\section{Информация об авторах | Author information}

RU Алферова Юлия Ивановна ${ }^{1}$, к. филол. н.

${ }^{1}$ Омская академия Министерства внутренних дел Российской Федерации

EN Alferova Yulia Ivanovna ${ }^{1}, \mathrm{PhD}$

${ }^{1}$ Omsk Academy of the Ministry of Internal Affairs of the Russian Federation

${ }^{1}$ yuliya_alferova@mail.ru

\section{Информация о статье | About this article}

Дата поступления рукописи (received): 12.01.2021; опубликовано (published): 09.04.2021.

Ключевые слова (keywords): идентифицирующая функция слова; ассоциативный прайминг; учебный билингв; профессионально ориентированный иноязычный текст; ассоциативный эксперимент; identifying word function; associative priming; foreign language learner; professionally oriented foreign-language text; associative experiment. 